\section{HUBUNGAN ANTARA PENGETAHUAN TENTANG PERAWATAN ORGAN REPRODUKSI DENGAN TINDAKAN PERSONAL HYGIENE PADA REMAJA PUTRI DI SMP 2 SOCAH}

THE RELATIONSHIP BETWEEN KNOWLEDGE OF REPRODUCTIVE ORGANS TREATMENT WITH PERSONAL HYGIENE ACTION ON GIRLS IN SMP 2 SOCAH

\section{ZURYATY *)}

RAHMAD SEPTIAN REZA *)

*) Sekolah Tinggi IImu Kesehatan Ngudia Husada Madura

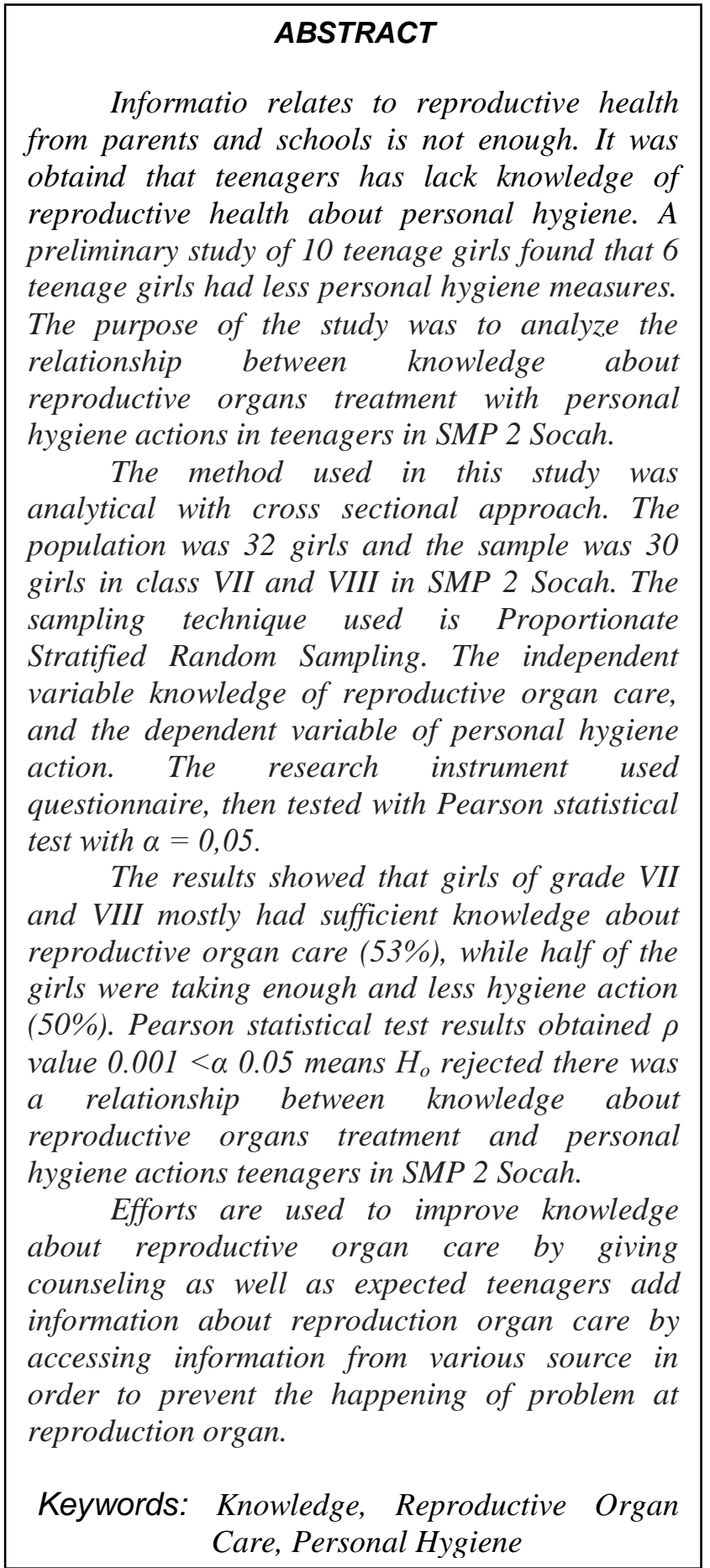

Correspondence: Zuryaty, Jl. R.E. Martadinata No. 45 Bangkalan,Indonesia. 


\section{PENDAHULUAN}

Remaja merupakan peralihan masa anak-anak menuju dewasa. Menurut WHO, batasan umur remaja antara usia 10-19 tahun. Perubahan psikis, soaial, dan fisik merupakan tanda seseorang menuju masa remaja. Terjadinya perubahan fisik merupakan aspek yang paling utama sehingga adanya perubahan anatomi dan fisiologi pada remaja tersebut (Marmi, 2013). Kematangan organ reproduksi pada remaja dapat terjadi secara cepat yang ditandai dengan perubahan fisik (Aryani, 2010).

Kebersihan organ reproduksi merupakan factor terpenting dan menjaga kebersihan diri. Kebersihan diri terutama organ reproduksi didapatkan melalui kesadaran dan informasi kesehatan (Mardalena, 2015).

Kebersihan individu dilakukan dengan menjaga kesehatan dan kebersihan. Tindakan tersebut harus diperhatikan oleh tiap individu dalam menuju kesejahteraan psikis dan fisik (Laily dan Sulistyo, 2012 dalam Permatasari, 2012).

Hasil penelitian yang dilakukan oleh Permatasari, 2015 dengan melakukan wawancara langsung kepada remaja putri di SMKN 02 Bangkalan didapatkan bahwa dari 10 responden, 3 responden mengatakan mengganti pembalut 2 kali per hari, mengganti pembalut setiap kali buang air kecil, mengganti celana dalam 1 kali per hari dan 7 responden mengatakan tidak mengganti saat buang air kecil, ganti pembalut 2 kali per hari, ganti celana dalam jika kotor alasannya selama sudah mengganti pembalut, kebersihan sudah terjaga. Sebagian besar remaja putri tidak mendapatkan informasi menjaga kebersihan daerah genetalia dari orang tua melainkan dari sumber-sumber yang lain.

Dari hasil studi pendahuluan pada tanggal 10 desember 2016 terhadap 10 remaja putri kelas VIII di SMP 2 Socah di dapatkan bahwa 6 siswi (60\%) memiliki tindakan personalhygiene yang kurang karena mereka tidak rutin untuk mengganti pembalut saat menstruasi, Dari hal ini disimpulkan masih rendahnya tindakan personal hygiene pada remaja putri SMPN 2 Socah.

Kesehatan organ reproduksi yang mengalami masalah dapat dipengaruhi oleh kurangnya pengetahuan dan adanya rasa malu utk bertanya kepada orang lain terutama pada petugas kesehatan (Ratna, 2010 dalam Yunika, 2013).

Menjaga kebersihan organ kewanitaan merupakan hal utama harus dilakukan. Hal tersebut dapat dilakukan dengan pencegahan infeksi. infeksi yang terjadi disebabkan oleh kebersihan yang buruk yang ditandai dengan kemerahan, gatal-gatal, iritasi, dan rasa perih pada oragn kewanitaan (Baradero, 2007 dalam Yunika, 2013).

Upaya yang dapat dilakukan oleh petugas kesehatan adalah memberikan penyuluhan kepada perempuan tentang bagaimana cara menjaga kebersihan alat kewanitaan (vulva hygiene), misalnya cara cebok yang benar untuk mencegah pindahnya bakteri dapat dilakukan dari depan ke belakang ke depan, kemudian dikeringkan dan penggunaan celana dalam yang baik, seberapa banyak harus ganti celana dalam yang dilakukan seperti yang telah dijelaskan oleh tenaga kesehatan (Suhartami, 2015).

\section{METODE PENELITIAN}

Penelitian yang dilakukan menggunakan pendekatan cross sectional dengan jenis analitik.

\section{HASIL PENELITIAN}

\section{Data Umum dan Data Khusus}

Tabel 1 Distribusi frekuensi responden berdasarkan umur di SMP 2 Socah

\begin{tabular}{cccc} 
No. & Umur & Frekuensi & Persentase (\%) \\
\hline 1 & 13 & 11 & 36,7 \\
2 & 14 & 17 & 56,7 \\
3 & 15 & 2 & 6,7 \\
\hline \multicolumn{5}{c}{ Total } & 30 & 100 \\
\multicolumn{3}{c}{ Sumber: Data Primer, Maret 2017 }
\end{tabular}

Dari tabel 1 di dapatkan karakteristik responden menunjukkan bahwa sebagian besar umur remaja putri adalah 14 tahun yaitu sebanyak 17 responden (56,7\%).

Tabel 2 Distribusi frekuensi responden berdasarkan sumber informasi di SMP 2 Socah

\begin{tabular}{|c|c|c|c|}
\hline No. & $\begin{array}{c}\text { Sumber } \\
\text { Informasi }\end{array}$ & Frekuensi & $\begin{array}{c}\text { Persentase } \\
(\%)\end{array}$ \\
\hline 1 & Orang tua & 21 & 70 \\
\hline 2 & Media Sosial & 5 & 17,7 \\
\hline 3 & Pacar & 0 & 0 \\
\hline \multirow[t]{2}{*}{4} & Teman & 4 & 13,3 \\
\hline & Total & 30 & 100 \\
\hline 00 & $\begin{array}{l}\text { Sumber: Data } p \\
\text { Dari tabel } \\
\text { nden menunj } \\
\text { remaja put } \\
\text { asi tentang pe }\end{array}$ & $\begin{array}{l}\text { rimer, } \text { Maret } \\
\text { ditemuka } \\
\text { ukkan bah } \\
\text { i mendap }\end{array}$ & $\begin{array}{l}017 \text { karakteri } \\
\text { wa sebag } \\
\text { tkan sum }\end{array}$ \\
\hline
\end{tabular}


dan personal hygiene dari orang tua sebanyak 21 responden $(70 \%)$.

Tabel 3 Distribusi frekuensi responden berdasarkan pekerjaan ibu di SMP 2 Socah

\begin{tabular}{clcc}
\hline No. & $\begin{array}{c}\text { Pekerjaan } \\
\text { lbu }\end{array}$ & Frekuensi & $\begin{array}{c}\text { Persentase } \\
(\%)\end{array}$ \\
\hline 1 & Petani & 4 & 13,3 \\
2 & Swasta & 0 & 0 \\
3 & Wiraswasta & 5 & 16,7 \\
4 & PNS & 0 & 0 \\
5 & Ibu rumah & 21 & 70 \\
\hline & tangga & 30 & 100 \\
\hline
\end{tabular}

Sumber: Data primer, Maret 2017

Dari tabel 3 di atas diketahui karakteristik responden menunjukkan bahwa sebagian besar pekerjaan orang tua terutama ibu adalah ibu rumah tangga sebanyak 21 responden (70 $\%)$.

Tabel 4 Distribusi frekuensi responden pengetahuan tentang perawatan organ reproduksi di SMP 2 Socah.

\begin{tabular}{ccc}
\hline $\begin{array}{c}\text { Tingkat } \\
\text { Pengetahuan }\end{array}$ & Frekuensi & $\begin{array}{c}\text { Persentase } \\
(\%)\end{array}$ \\
\hline Baik & 0 & 0 \\
Cukup & 16 & 53,3 \\
Kurang & 14 & 46,7 \\
\hline Total & 30 & 100 \\
\hline
\end{tabular}

Sumber: Data primer, Maret 2017

Berdasarkan hasil penelitian sebagian besar remaja putri memiliki pengetahuan yang cukup terhadap perawatan organ reproduksi sebanyak 16 remaja putri (53,3\%).

Tabel 5 Distribusi frekuensi responden tindakan personal hygiene pada remaja putri di SMP 2 Socah.

\begin{tabular}{ccc}
\hline $\begin{array}{c}\text { Tingkat } \\
\text { Tindakan }\end{array}$ & Frekuensi & Persentase (\%) \\
\hline Baik & 0 & 0 \\
Cukup & 15 & 50 \\
Kurang & 15 & 50 \\
\hline Total & 30 & 100 \\
\hline \multicolumn{4}{l}{ Sumber: Data primer, Maret 2017 } \\
Berdasarkan & hasil penelitian dapat \\
diketahui bahwa & setengahnya remaja putri \\
memiliki tindakan personal hygiene cukup dan \\
kurang sebanyak 15 remaja putri (50 \%).
\end{tabular}

Tabel 6 Tabulasi silang hubungan antara pengetahuan tentang perawatan organ reproduksi terhadap tindakan personal hygiene remaja putri di SMP 2 Socah.

\begin{tabular}{|c|c|c|c|c|c|c|c|}
\hline \multirow{3}{*}{$\begin{array}{l}\text { Pengetahuan } \\
\text { perawatan } \\
\text { organ } \\
\text { reproduksi }\end{array}$} & \multicolumn{5}{|c|}{ Tindakan personal hygiene } & \multirow{2}{*}{\multicolumn{2}{|c|}{ Jumlah }} \\
\hline & Baik & \multicolumn{2}{|c|}{ Cukup } & \multicolumn{2}{|c|}{ Kurang } & & \\
\hline & F $\%$ & $\mathbf{F}$ & $\%$ & $\mathbf{F}$ & $\%$ & $\Sigma$ & $\%$ \\
\hline Baik & 0 & 0 & 0 & 0 & 0 & 0 & 0 \\
\hline Cukup & 0 & 15 & 50 & 1 & 3,3 & 16 & 53,3 \\
\hline Kurang & 0 & 0 & 0 & 14 & 46,7 & 14 & 46,7 \\
\hline Jumlah & 0 & 15 & 50 & 15 & 50 & 30 & 100 \\
\hline \multicolumn{8}{|c|}{ Uji statistik Pearson $P=0,001<\alpha=0,05$} \\
\hline \multicolumn{8}{|c|}{$\begin{array}{l}\text { Sumber: Data primer, Maret } 2017 \\
\text { Berdasarkan tabel } 6 \text { dapat disimpulkan } \\
\text { bahwa sebagian besar } 16 \text { remaja putri (53,3\%) } \\
\text { mempunyai pengetahuan perawatan organ } \\
\text { reproduksi yang cukup dan setengahnya } 15 \\
\text { remaja putri (50\%) melakukan tindakan } \\
\text { personal hygiene yang cukup, dan hampir } \\
\text { setengahnya } 14 \text { remaja putri (46,7\%) } \\
\text { mempunyai pengetahuan perawatan organ } \\
\text { reproduksi yang kurang dan setengahnya } 15 \\
\text { remaja putri (50\%) melakukan tindakan } \\
\text { personal hygiene yang kurang. }\end{array}$} \\
\hline
\end{tabular}

Hasil uji statistik Pearson menunjukkan nilai signifikan $\rho$ value $<\alpha$ atau 0,001 $<0,05$ sehingga $H_{0}$ ditolak, yang bermakna "Ada hubungan antara pengetahuan perawatan organ reproduksi dengan tindakan personal hygiene pada remaja putri di SMP 2 Socah".

\section{PEMBAHASAN}

\section{Gambaran pengetahuan tentang perawatan organ reproduksi}

Berdasarkan hasil penelitian yang diperoleh menunjukkan bahwa dari 30 responden sebagian besar yang mempunyai pengetahuan tentang perawatan organ reproduksi yang cukup yaitu 16 remaja putri $(53,3 \%)$. Adapun hasil kuesioner yang diberikan kepada 30 responden ada dua pertanyaan yang nilainya tergolong tinggi tentang penggunaan sabun pembersih vagina yang terlalu sering sedangkan ada satu pertanyaan yang nilainya tergolong rendah tentang frekuensi mengganti pembalut saat hari pertama menstruasi.

Hal ini berkaitan dengan tingkat pengetahuan, yaitu kehidupan remaja putri di lingkungan sekitar atau lingkungan pendidikan, dimana di lingkungan sekitar remaja tersebut dibesarkan, akan memberikan pengaruh terhadap pengetahuan yang dimiliki oleh remaja tersebut. Penerimaan informasi tentang 
perawatan organ reproduksi dari orang tua, teman, guru di lingkungan sekolah dan kemudahan mendapat informasi dapat membantu seseorang untuk memperoleh pengetahuan.Orang tua memiliki peranan penting dalam mendidik dan memberikan pengetahuan kepada anaknya sehingga dapat menciptakan pandangan atau perilaku tertentu terhadap masalah. Hal ini sesuai dengan pernyataan Rohmah (2016) bahwa pemahaman dan wawasan yang luas di dapatkan melalui informasi terutama informasi kesehatan terhadap organ reproduksi wanita.

Dari hasil penelitian di atas tidak ada satupun remaja putri yang mempunyai pengetahuan baik karena remaja putri hanya mendapatkan informasi dari ibunya saja, remaja putri kurang memanfaatkan informasi dari media massa, penyuluhan dan buku tentang perawatan organ reproduksi sehingga wawasan yang didapat kurang luas. Hal ini sesuai dengan pernyataan Maidartati (2016) bahwa pengetahuan yang baik diperoleh dari informasi. Informasi yang didapatkan melalui media massa seperti penyuluhan, elektronik, media cetak dan sumber lainnya.

Tingkat pengetahuan perawatan organ reproduksi dapat dikaitkan dengan umur, dan sumber informasi. Dimana berdasarkan hasil penelitian terdapat sebanyak 5 responden yang memiliki pengetahuan cukup yang berumur 13 tahun, sedangkan 9 responden yang memiliki pengetahuan cukup berumur 14 tahun. Hal ini sesuai dengan pendapat Fitriyah (2014) bahwa semakin berkembangnya pola pikir dan meningkatnya usia, akan mempengaruhi pengetahuan yang baik.

Hasil penelitian di temukan sebanyak 13 responden yang memiliki pengetahuan cukup mendapatkan informasi dari orang tua terutama ibu. Dan sebanyak 1 responden yang memiliki pengetahuan cukup mendapatkan informasi dari media sosial. Dari data tersebut didapatkan banyak responden yang memiliki pengetahuan cukup mendapatkan informasi dari orang tua yaitu ibu. Hal ini dikarenakan sumber informasi yang mereka dapatkan sebagian besar dari orang tua yaitu ibu, karena mereka lebih dekat dengan ibunya dan ibu lebih memahami tentang organ reproduksi.Jika pengetahuan yang diperoleh dari informasi yang baik, maka usaha remaja dalam merawat organ reproduksi akan tinggi dan akan menggunakan cara yang benar. Sebaliknya jika pengetahuan yang kurang dan diperoleh dari informasi yang salah, maka usaha remaja dalam merawat organ reproduksi akan rendah. $\mathrm{Hal}$ ini sesuai dengan pendapat Puspitaningrum (2012) bahwa pendidik utama bagi seorang anak adalah orang tua. Melalui orang tua anak merasa diperhatikan sehingga informasi kebersihan organ reproduksi dapat diterima dengan baik dan diterapkan oleh remaja wanita tersebut.

\section{Gambaran tindakan personal hygiene}

Hasil penelitian yang diperoleh dari 30 responden, sebagian besar remaja putri yang melakukan tindakan personal hygiene cukup dan kurang sebanyak 15 remaja putri $(50 \%)$, adapun hasil kuesioner yang diberikan kepada 30 responden ada satu pertanyaan yang nilainya tergolong tinggi tentang cara membasuh alat kelamin dari arah depan ke belakang sedangkan ada satu pertanyaan yang nilainya tergolong rendah tentang merapikan rambut kemaluan dengan cara mencukur atau menggunting.

Berdasarkan jawaban dari responden tiap item pertanyaan bahwa responden membersihkan kemaluan dari arah depan ke belakang sebanyak $84 \%$, dan responden membungkus pembalut dengan plastik sebelum di buang ketempat sampah sebanyak $63 \%$, serta responden mengganti celana dalam 2 kali sehari sebanyak $57 \%$. Pada penelitian ini didapatkan tindakan yang cukup hal ini merupakan kebiasaan sejak awal yang dilakukan oleh keluarga secara rutin sehingga rutin dilakukan secara tepat dan sehat.

Tetapi masih ada juga memiliki tindakan kurang berdasarkan jawaban responden dari pertanyaan bahwa responden memakai celana dalam yang tidak menyerap keringat sebanyak $62 \%$, kemudian setiap hari responden menggunakan sabun antiseptik ketika membersihkan kemaluan sebanyak $64 \%$, dan responden tidak rutin mengganti pembalut saat menstruasi sebanyak 44\%. Hal ini mungkin dipengaruhi oleh persepsi remaja putri yang lebih memilih alasan praktis dan mudah daripada harus memelihara kebersihan organ genetalia yang terlalu ribet seperti rutin mengganti pemabalut.

Dari hasil kuesioner di atas, menurut Pribakti (2010), membersihkan dari arah belakang dapat mempermudah perpindahan bakteri, sehingga menimbulkan infeksi. untuk mencegah infeksi tersebut, lakukan cara yang benar dengan membasuh dari arah depan depan ke belakang dan mengunakan air yang bersih. Sedangkan menurut Andira (2010), mencukur atau menggunting rambut perlu dilakukan untuk menjaga kebersihan. Alat cukur yang digunakan harus milik individu dan tidak boleh bergantian demi pencegahan infeksi organ reproduksi. 


\section{Hubungan antara pengetahuan tentang perawatan organ reproduksi dengan tindakan personal hygiene pada remaja putri di SMP 2 Socah}

Hasil penelitian yang diperoleh dari 30 responden, menunjukkan sebagian besar 16 remaja putri mempunyai pengetahuan perawatan organ reproduksi cukup dan setengahnya 15 remaja putri melakukan tindakan personal hygiene yang cukup. Berdasarkan uji statistik pearson di dapatkan nilai kemaknaan $P$ value $=0,001<\alpha=0,05$ dengan demikian $\mathrm{H} 1$ diterima dan $\mathrm{H} 0$ ditolak, maka terdapat hubungan antara organ reproduksi dengan tindakan personal hygiene terhadap pengetahuan pada remaja putri di SMP 2 Socah dan sifat antara keduanya memiliki hubungan yang positif artinya bahwa semakin tinggi pengetahuan maka semakin baik tindakan personal hygiene yang dimiliki remaja putri.

Semakin banyak pengetahuan yang diperoleh remaja putri tentang perawatan organ reproduksi maka remaja putri tersebut akan lebih mudah memahami dan melakukan kebersihan pada organ genetalianya. Jika pengetahuan yang diperoleh dari informasi yang baik, maka usaha remaja dalam merawat organ reproduksi akan tinggi dan akan menggunakan cara yang benar. Sebaliknya jika pengetahuan yang kurang dan diperoleh dari informasi yang salah, maka usaha remaja dalam merawat organ reproduksi akan rendah.

Hal ini sesuai dengan pernyataan Mardalena (2015) bahwa pengetahuan mempunyai keeratan hubungan dengan tindakan kebersihan organ genetalia eksterna artinya semakin baik pengetahuan mahasiswi maka kecenderungan mahasiswi untuk melakukan tindakan kebersihan organ genetalia eksterna akan semakin besar. Menurut notoatmodjo (2007) dalam Mardalena (2015), tindakan yang didasari pengetahuan akan lebih langgeng dibandingkan tanpa didasari pengetahuan.

Hal ini sesuai dengan pernyataan Isro'in (2012) faktor yang mempengaruhi personal hygiene salah satunya adalah pengetahuan. Menurut Notoatmodjo (2012) pengetahuan merupakan hal utama yang membentuk prilaku seseorang. Menurut teori Bloom domain perilaku ada 3 yaitu pengetahuan, sikap, dan tindakan.

Penelitian yang dilakukan oleh Rohmah (2016) dengan judul "Hubungan tingkat pengetahuan remaja putri tentang personal hygiene dengan perilaku personal hygiene di SMAN 01 Sewon Yogyakarta" yang menyatakan ada hubungan dengan kekuatan korelasi rendah dan arah hubungannya positif, artinya semakin tinggi pengetahuan semakin baik perilaku personal hygiene remaja putri.Penelitian tersebut diperkuat oleh penelitian yang dilakukan oleh Astuti (2016) menyatakan ada hubungan tingkat pengetahuan remaja putri tentang organ reproduksi dengan perilaku personal hygiene organ reproduksi.

Hal ini terlihat dari hasil pengumpulan data dari responden bahwa dengan pengetahuan yang cukup cenderung akan diikuti oleh tindakan yang cukup juga. Sedangkan responden dengan pengetahuan yang kurang akan diikuti oleh tindakan yang kurang. Jadi dapat disimpulkan bahwa pengetahuan sangat mempengaruhi tindakan personal hygiene seseorang.

\section{KESIMPULAN}

Terdapat hubungan antara pengetahuan tentang perawatan organ reproduksi dengan tindakan personal hygiene pada remaja putri di SMP 2 Socah.

\section{DAFTAR PUSTAKA}

Andira, Dita. 2010. Seluk-Beluk Kesehatan Reproduksi Wanita.Jogjakarta: $A^{+}$Plus Books

Aryani, Ratna. 2010. Kesehatan Remaja Problem dan Solusinya. Jakarta: Salemba Medika.

Astuti, Lilis Puji. 2016. Hubungan Tingkat Pengetahuan Remaja Putri dengan Perilaku Personal Hygiene Organ Reproduksi di SMP Negeri 3 Kedal. Di akses 2 maret 2017. http://182.253.197.100/ejournal/index.php/ilmukeperawatan/articl e/download/73/103

Fitriyah, Imarotul. 2014. Gambaran Perilaku Hygiene Menstruasi pada Remaja Putri di Sekolah Dasar Negeri di Wilayah Kerja Puskesmas Pisangan.Di akses 20 November 2016.http://repository.uinjkt.ac.id/dspace/ handle/123456789/24132

Isro'in, Laily dan Andarmoyo, Sulistyo. 2012. Personal Hygiene: Konsep, Proses, dan Aplikasi dalam Praktik Keperawatan. Edisi 1. Yogyakarta: Graha IImu.

Maidartati dkk. 2016. Hubungan Pengetahuan dengan Vulva Hygiene pada saat Menstruasi Remaja Putri. Di akses 16 Mei 
http://ejournal.bsi.ac.id/ejurnal/index.php/ jk/article/download/405/311

Mardalena, Ria Mistika dkk. 2015. Hubungan Pengetahuan dan Sikap dengan Tindakan Kebersihan Organ Genetalia Eksterna sebagai Upaya Pencegahan Keputihan pada Mahasiswi Fakultas Kesehatan Masyarakat Universitas Sumatera Utara. Di akses 26 Februari 2017.

http://202.0.107.5/index.php/gkre/article/ download/11497/6087

Marmi dan Margiyati. 2013. Pengantar Psikologi Kebidanan Buku Ajar Psikologi Kebidanan. Yogyakarta: Pustaka Pelajar.

Notoatmodjo, Soekidjo. 2012. Promosi Kesehatan dan Perilaku Kesehatan. Jakarta: Rineka cipta.

Permatasari, Mareta Wulan dkk. 2012. Hubungan Tingkat Pengetahuan Remaja Putri tentang Personal Hygiene dengan Tindakan Pencegahan Keputihan di SMA Negeri 9 Semarang. Di akses 28 Februari 2017. http://jurnal.unimus.ac.id/index.php/jur bi d/article/download/823/876

Pribakti. 2010. Tips dan Trik Merawat Organ Intim Panduan Praktis Kesehatan Reproduksi Wanita. Jakarta: CV Sagung Seto.

Puspitaningrum, Dewi. 2012. Faktor-faktor yang Mempengaruhi Praktik Perawatan Organ Genetalia Eksternal pada Anak
Usia 10-11 Tahun yang Mengalami Menarche Dini di Sekolah Dasar kota Semarang. Diakses 3 Mei 2017.http://jurnal.unimus.ac.id/index.php/ psn12012010/article/download/498/547

Rohmah, Muzayyinatul. 2016. Hubungan tingkat pengetahuan remaja putri tentang personal hygiene dengan perilaku personal hygiene di SMAN 01 Sewon Yogyakarta. Diakses 9 Mei 2017. http://repository.stikesayaniyk.ac.id/625/1 Muzayyinatul\%20Rohmah 2213018 no nfull\%20resize.pdf

Suhartami, Mei Rina. 2015. Personal Hygiene dengan Kejadian Flour Albus pada Santriwati di Pondok Pesantren Darut Taqwa Desa Ngambeh Kecamatan Dlanggu Mojokerto. Di akses 28 Februari 2017.

http://repository.poltekkesmajapahit.ac.id index.php/PUB-

KEB/article/download/289/244

Yunika, Regina Pricilia. 2013. Hubungan antara Pengetahuan Remaja Putri dengan Perilaku Menjaga Kebersihan Alat Genetalia pada Masa Pra Menarche di SD Negeri 2 Ungaran Barat. Di akses 27 Februari 2017. http://perpusnwu.web.id/karyailmiah/doc uments/3647.docx 